\title{
A Literature Review of Treasury Bond Futures Pricing and Arbitrage Method
}

\author{
Susheng Wang ${ }^{1, a^{*}}$,Yongrui Yu ${ }^{2, b,{ }^{*}}$ and Huimin Liu ${ }^{3, c}$
}

${ }^{1}$ School of Urban Planning and Management, Harbin Institute of Technology Shenzhen Graduate School, HITSGS Campus, Shenzhen University Town

Shenzhen, 518055, China

${ }^{2}$ School of Urban Planning and Management, Harbin Institute of Technology Shenzhen Graduate School, HITSGS Campus, Shenzhen University Town

Shenzhen, 518055, China

${ }^{3}$ School of Urban Planning and Management, Harbin Institute of Technology Shenzhen Graduate School, HITSGS Campus, Shenzhen University Town

Shenzhen, 518055, China

a611197033@qq.com, byyr215@qq.com, c1519461853@qq.com

Keywords: treasury bond futures; holding cost method; CTD bond

Abstract.5-year and 10-year term treasury bond futures were launched officially in September 6, 2013 and March 20, 2015, marking the interest rate futures re-board the stage of history. Academic study of treasury bond futures gradually becomes a hot issue, this article describes the difficult and hot issues at home and abroad from the aspects of futures pricing theory, the relationship between the spot and arbitrage.

\section{Introduction}

The world's first treasury bond futures were launched by the Chicago Mercantile Exchange (CME) in United States in 1976. The subject of this futures contract is 90-day short-term Treasury bills. In 2011, the volume of 10-year treasury bond futures on the Chicago Board of Trade reached 317 million board lot, becoming one of the most active trading varieties in world's treasury bond futures market. In 30 years, the treasury bond futures market has been rapid development and become a relatively mature futures products.

Table1-1 listed time of treasury bond futures in some counties

\begin{tabular}{cccc}
\hline country & variety & time & exchange \\
\hline $\begin{array}{c}\text { American } \\
\text { Britain }\end{array}$ & $\begin{array}{c}\text { 91-day Treasury bonds } \\
\text { 20-year British government } \\
\text { gilts }\end{array}$ & 1976.01 & CME \\
Japanese & $\begin{array}{c}\text { 10-year Japanese } \\
\text { government bonds }\end{array}$ & LIFFE \\
& 7 -10-year French bond & 1986.10 & TSE \\
French & Long-term Treasury bonds & 1990.11 & MATIF \\
Germany & 3-year bonds & 1999.09 & DTB \\
Korea & & & KOFEX \\
\hline
\end{tabular}

Data source: Wind Info

In the end of 1992, China began to trade treasury bond futures. After June 1994, with the increase of participants, turnover gradually became active again and only annual turnover of the Shanghai Stock Exchange reached nearly 2 trillion. Because of related management systems flawed, speculation atmosphere is very strong which caused the outbreak of shocking "327" event on February 23, 1995. On May 11, after a lapse of three months, "319" incident came out, so treasury bond futures were suspended. China Securities Regulatory Commission issued a "emergency notice on nationwide suspension of treasury bond futures pilot project" on May 17, 1995, hastily declaring China treasury bond futures failed. In the new century, Chinese government continues to promote market-oriented interest rate, treasury bond futures re-listed on the agenda. On February 13, 2012, China Financial Futures began simulation trading test on treasury bond futures. On April 23, 2012, 
treasury bond futures simulation trading began pushing to the full market. On September 6, 2013, Treasury bond futures traded officially on CFFE, it became academic research focus.

\section{Futures Pricing Theories}

Capozza and Cornell (1979) testing the treasury bond futures market under the no-arbitrage pricing theory [1]. Chow and Brophy (1982) took the Chicago Mercantile Exchange data as an example to study the pricing of treasury bond futures contracts and eventually found the price trend deviation between spot and futures is high and the market was lacking of efficiency. The price discovery function of the market has not been a real play [2]. Cornell and French (1983) by amendments to the simple arbitrage model, proposed holding cost model based on the assumption of a perfect market. However, due to the assumption of the model ignores the market environment factors, led to a significant difference between the actual price and theoretical futures prices [3]. Hegde and Branch (1985) got the same conclusion with Cornell and French when researching treasury bond futures contract pricing for CME [4].

Kane and Marcus (1986) estimated the term structure of CTD bond by estimating the futures contract expiration date, using government bonds yield to maturity information in 1978-M1-1982-M12 do the cross-sectional regression and take the month as a sample:

$$
y=b_{0}+b_{1} T^{\frac{1}{2}}+b_{2} T+b_{3} T^{2}+b_{4} T+\operatorname{coupon}\left(C_{0}+C_{1} T\right)
$$

Then they using 59 different data of 60 months do a differential to the regression coefticients of adjacent two months, the paper estimated the coefficient distribution and obtained the yield term structure coefficient distribution when the futures contract expires using Monte Carlo simulation method. Further obtaining the CTD bond on each of interest rate path, the paper found the value of the option selected using this distribution. The estimated price of the option selected coupons is about $1.9 \%-6.2 \%$ of futures contract prices [5].

Richard (2004) conducted a model for instantaneous spot free risk interest rate by BDT model, which obtained futures price were considered the selected coupon option and got the corresponding value of option selected. Secondly, the article also received hedge ratio by treasury bond futures to hedge the cheapest bond delivery. Research of the article showed that: when it was assumed interest rate term structure was smooth, and interest rates stood at around $6 \%$, based on the traditional current cheapest ticket delivery hedge ratio variation range was large, and therefore, cannot achieve a good interest rate risk hedging. And when interest rates were significantly different from $6 \%$, hedge ratio obtained based on the current cheapest bond delivery duration was more accurate [6]. Daniel LT (2004) using VAR model of the JGB market data carried on expected test and found that in the stable interest rate assumptions, expectations theory cannot be supported; whereas in the interest of non-stationary conditions, expectations theory can be supported, but need cointegration relationship between short-term interest rates and long-term interest rates [7].

Domestically, Xiaoling Luo et al. (2003) used holding cost model of commodity futures in financial futures pricing, and aiming at the net cost of holding characteristics for holding foreign currency futures, interest rate futures, stock index futures contracts derived pricing model of foreign currency futures, interest rate futures and stock index futures [8]. Shiwu Zhu and Jianheng Chen used polynomial spline model and NS-adjusted model to research spot market of treasury bond future, and found that the advantages of polynomial spline was fit for long-term interest rates, but due to the power rose it was very sensitive to the sample data, which was highly likely to affect the curve fitting results $[9,10]$.

Alejandro B and Susana R (2010) using data from the German treasury bond futures, adopted option selected bonds definition differs from the definition of their predecessors, which is defined as follows (predecessors definition is $\mathrm{min}$ ):

$$
\max \left(\frac{p_{o, j}}{\delta_{j}}-\frac{f}{(1+r)^{T}}\right) \text { (2) }
$$


Using non-arbitrage method select option prices from market prices, the paper found that on the German treasury bond futures market, the value of the option selected coupons decreased as futures contracts approaching expiration date, so you can perform trend arbitrage. This approach has a certain similarity with selling the largest basis of deliverable bonds, so you can choose to sell the options to select bonds, then buy them in the future, so substantial arbitrage income can obtain [11].Grieves and Marcus (2010) [12] used bond future and note future of CBOT transaction to empirically test the article of Grieves and Marcus (2005) [13] and found that the results obtained using only two deliverable bonds (highest duration and the lowest duration deliverable bonds) method is consistent with the results obtained in note future market.

R Ben-Abdallah, H Ben-Ameur and M Bretor (2012) took into account the option to choose time and the option to choose bonds for the treasury bond futures contract pricing and used Vasicek model, CIR model and HW models for modeling the spot interest rate to give Numerical solution of treasury bond futures prices. The study found that in the two months before the delivery time, the market price of treasury bond futures is lower on average about $2 \%$ than the theoretical price, indicating that if the HW model is suitable for the modeling of interest rates, the market overestimated the value of the option selected bonds [14].

Domestically, Ying Chen(2012) indicates the CTD bond is less likely to change, which means that delivery option value was smaller [15]. Canquet (2013) proposed a treasury bond futures pricing linear regression model to study the influence of delivery options in the futures pricing. This model did not give a pricing formula to resolve, but using treasury bond futures market transactions data, and through empirical analysis to study the impact of delivery options on treasury bond futures pricing [16]. Mao Ran(2013) did not agree with simplistic holding cost pricing, thinking the option of choice could cause that the actual futures price will deviate from the expected value of futures. Under this assumption, he analyzed the yield to maturity on choice of options and found that the nature of the option was exchanging option which exchanges existing CTD bond with blanket bonds when futures contracts expired. Capacity of the bond market, the issuance of new bonds, bonds liquidity, interest rates changes and other factors would affect bond prices when the contract expires, thereby affecting value of choosing option. In the calculation of the value of the options, selecting the gradual increase the number of simulations, the paper described the situation that the option value gradually stabilized with the increase number of simulations. Result showed that the value of the option was about 1.48, corresponding to the face value of 100 RMB contract [17]. Chao Sun (2014) introduced Margrabe binary asset swap option pricing model to price delivery option and empirically analyzed the size of delivery options after treasury bond futures listed in China market and then analyzed their applications. Delivery options of our country's treasury future worth an average of $0.132 \mathrm{RMB}$, accounting for $0.132 \%$ of par value, indicating that the option has a certain value [18]. Chaithanya and Dimitris priced the option by combining with robust optimization and arbitrage [19].

In 2012, Ying Song calculate the theory price range of treasury bond futures in friction market using the holding cost model, used the US market transaction data find that long-term treasury bond futures was more prone to appear arbitrage opportunities than the medium-term treasury bond futures contract, the longer the remaining term of the contract, the more the number of occurrences of arbitrage. 13 treasury bond futures contracts had all appeared low frequency arbitrage opportunities and limited arbitrage opportunities occur mostly in the contract just listed. In the treasury bond futures market, the number of treasury bond futures contract price been undervalued is far more than overvalued, so reverse arbitrage opportunities far beyond the number, scale and frequency of positive arbitrage [20]. Chunjia Zhang(2013) predicted that 5-year treasury bond futures would have the opportunity of arbitrage through vertical and horizontal data analysis [21].

\section{The Study of Relationship between Futures and Spot}

After 30 years development, treasury bond futures have become the major financial futures varieties in the world. The development experience of the treasury bond futures market of developed countries shows that, treasury bond futures will play an important role in improving the 
pricing function of bond market, promoting the liquidity of the spot market and enriching the means of interest rate risk management of bond investors, and will also add new profit model for investors. With treasury bond futures' basic function of avoiding interest rate risk and price discovery, the trading of treasury futures play a positive role in promoting the development of primary market and secondary market.

William Poole (1978) put forward that there is also has significant correlation between spot and futures, which are closest to the current period, even has transaction cost [22].

Zheng Wang etc. (1994) established the multi-objective planning and optimization decision model under the constraint conditions of transaction cost and opportunity loss. The characteristic of this kind of method is the pursuit of hedging portfolio minimization [23].

Leuthold (1974) [24], Martin and Carcia (1981) [25], Hokkio Rush (1989) [26], Bhattacharya and Smgh (2007) [27] etc. still regarded the futures price can't unbiased estimate future spot price as an evidence of market was invalid. Recently, many scholars' researches have shown that, as a result of the existence of varieties of transaction cost, the spot-future arbitrage cannot be fully realized. And as hedgers pay more attention to the transfer of risk rather than the determination of price, so speculators exert a greater impact on the formation of futures price. Therefore, in many cases, the future price is not unbiased estimates of future price in the real world.

Rong Chen and Zhenrong Zheng (2008) [28], who came from Xia Men university, studied the relationship between the futures price and spot price. Due to treasury bond futures were not be launched at that time, they just proved theoretically that, in the general case, the futures price was not the unbiased expectation of future spot price, and thought that the futures market should be divided into two categories, including pricing efficiency and information efficiency.

In empirical aspects, they put forward three kinds of model, which were suitable for inspecting the futures and spot price relationship, and respectively used co-integration test, Granger causality test and Broad spectrum analysis method, on the basis of the above conclusions, to test the pricing efficiency, price lead-lag relationship and information efficiency of spot and futures market of S\&P 500 index on September 21, 1990 to December 20, 2007. Xianghui Cai (2009) [29], analyzed the daily data of HSI futures and spot in May 1986 to September 2009 and 5 minutes data on March 6, 2009 to September 4, 2009. And he finally concluded that the higher frequency of the empirical data, the greater contribution amounts of the futures market price discovery.

Renhai Hua and Qingfu Liu (2010) used modified MIS model and 1 minute high frequency data to study the price discovery function of SPIF and spot market in our country, and found that the contribution amounts of SPIF market accounted for 75\%, stock index spot market just 25\% [30].

Through the establishment of joint decision model of the futures price and spot price, Yingying Xing (2012) studied the conditions of futures price and spot price tend to be stable and converge to the mean value of future spot, and empirically examined the impact of commodity futures trading in our country on spot prices [31].

Empirical studies of Zhen Wang(2013) has shown that the introduction of treasury bond futures has really improved the efficiency of information dissemination in the spot market. But it did not affect the volatility of the respective countries, which means that the volatility of the spot market trend neither increase nor reduce [32]. Jian Ma found that in Chinese market treasury market changes before the change in the futures market, which was opposite to the price discovery function of futures [33]. In Chinese treasury bond futures market, the spot and future price changes in response to the impact of each other was 12 cycle, 2 to 3 times of the international standard. These have shown that Chinese treasury bond futures market could be given related policies to promote the development of the market, then treasury bond futures market could more accurately reflect the impact of market information impact and achieve the function of market price discovery timely feedback to information.

\section{Arbitrage Theory Research}

HowardC $\mathrm{T}$ et al.(1984) pursued the objective of maximizing the Sharpe ratio, established a futures hedging optimization model and theoretically derived futures hedge ratio [34]. 
Mitchell, Pulvino and Stafford's (2002) study showed that arbitrage could accurately price financial products and to maintain efficient operation of the market, which was an important point of view in financial economic area. In complete market could get a certain value of financial assets, while in the non-perfect futures market, got a range of financial asset prices [35]. Andrea A (2012) discussed the impact of arbitrage, single factor, multi-factor term structure model, and market frictions of US treasury market on no-arbitrage term structure model [36]. Yang Yang (2014) built treasury bond futures and spot risk-free arbitrage portfolio, using static price daily data measured the possible risk-free arbitrage (spot held for trading) gains from September 6, 2013 to November 29 [37].Marcelo P (2014) analyzed the determinants of cross-platform arbitrage profits and proposed a structural model to break down possible arbitrage opportunities for three different factors which were the fixed costs of the business opportunity, the influence that a platform deferred updates price levels and offer price instruction stream (influence of inventory and information asymmetry). The results showed that cross-market arbitrage opportunities had a degree of predictability in a best beforehand scene: a low level of information dissemination, the end of the transaction time and a lot of transactions [38]. Lin Guan (2015) based on the empirical data of official trading of treasury bond futures and statistical arbitrage method, empirically researched on inter-temporal treasury bond futures trading strategies. It proposed cross-period CAPM commodity specification based on the pressure variable of storage and hedging theory [39]. Han $\mathrm{CH}$ (2015) analyzed the hedging robustness of stock index market, introduced two types of hedging transactions: model-free and Volatility-Model-Free, and using corrected Fourier transform method to estimate instantaneous fluctuations. Based on price limit rules in Taiwan market, the paper proposed varying methods on time scales [40]. Liang CX and Li SH (2015) developed a stable normal distribution whose term has random fluctuations to capture implied volatility characteristics and derive real option pricing and hedging formulas, then empirically compare four option pricing model [41].

\section{Summary}

This paper described the latest developments of the current domestic and foreign academics and practitioners from three aspects which are futures pricing, the relationship between futures and spot as well as arbitrage research. The paper analyzed the strengths and weaknesses and limitations of the various methods and the relevant staff can continue to study in depth according to their research interests and direction.

\section{References}

[1] Capozza, Dennis, Bradford Cornell. Treasury bill pricing in the spot and futures market [J]. The Review of Economics and Statistics, 1979(4):513-520.

[2] Chow B G, Brophy D J. Treasury Bill Futures Market a Formulation and Reinterpretation [J]. Journal of Futures Market, 1982, 2(01).

[3] Cornell B, French K. The Pricing of Stock Index Futures [J]. Journal of Future Markets, 1983:1-14.

[4] Hegde S P, Branch B. An Empirical Analysis of Arbitrage Opportunities in the Treasury Bill Futures and Market [J]. Journal of Futures Market, 1985, 5(3):407-424.

[5] Kane A, Alan J Marcus. The Quality Option in Treasury Bond Futures Market: An Empirical Assessment [J]. Journal of Futures Markets, 1986:231.

[6] Richard J Rendleman. Delivery Options in the Pricing and Hedging of Treasury Bond and Note Futures [J]. Journal of Fixed Income, 2004(14):20-31.

[7] Daniel L Thornton. Testing the Expectations Hypothesis: Some New Evidence for Japan[J]. Monetary and Economic Studies, 2004(5):45-69.

[8] Xiaoling Luo, Yizhi LI, Honghao Rao. Holding costs theorymodel in the application of financial futures pricing[J]. Journal of Central South University (social science edition), 2003, 9(6):013. 
[9] Shiwu Zhu, Jianheng Chen. empirical research on interest ratesterm structure ofExchange treasury[J]. Financial research, 2003(10):13-16.

[10] Shiwu Zhu, Jianheng Chen.Empirical test on interest rate term structure theory and term risk premium[J]. Financial research, 2004, 287(5):78-88.

[11]Balbas A, Reichardt S. On the Future Contract Quality Option: a New Look [J].Applied Financial Economics, 2010(20):1217-1229.

[12] Grieves R, Alan J Marcus, Woodhams A. Delivery Options and Convexity in Treasury Bond and Futures [J]. Review of Financial Economics, 2010(19):1-7.

[13] Grieves R, Marcus A J , Delivery Options and Treasury Bond Futures Hedge Ratios[J]. Journal of Derivatives, 2005(13):2.

[14]Ben-Abdallah, R Hatem Ben-Ameur and Michele Breton, Pricing the Chicago Board of Trade T-Bond Futures [J]. Quantitative Final, 2012(12):1663-1678.

[15] Ying Chen. Government bond futures transformation options[N]. Futures Daily, 2012-9-13.

[16] Kai Kang, Jin Pan. Empirical research on relations between bond futures pricing and delivery options[J]. Times Finance, 2014(4):159-161.

[17] Mao Ran. Treasury futures choose delivery option pricing under the CIR model[D]. Chengdu : Southwestern University of Finance, 2013.

[18]Chao Sun. China's treasury futures delivery options pricing and empirical research[J]. Contemporary Economics, 2014(18): 130-131.

[19] Chaithanya B, Dimitris B. Robust option pricing [J]. European Journal of Operational Research, 2014, 239:842-853.

[20] Ying Song. An empirical analysis of the treasury futures arbitrage opportunities-taking US Treasury futures markets as an example[J].Price Theory and Practice, 2012(8):68-69.

[21]Chunjia Zhang. Application research on China's treasury futures arbitrage strategy [D]. Shanghai : Shanghai Jiaotong University, 2013.

[22]Poole, William, Using T-bill Futures to Gauge Interest-Rate Expectations [J]. Federal Reserve Bank of San Francisco Economics Review, 1978:7-19.

[23]Zheng Wang, Zhiping Fan, Quan Zhang. The multiphase multi-objective programming model of futures hedging[J]. SystemsEngineering, 1997, 15(2):50-53.

[24]Leuthold R M. The Price Performance on the Futures Market of a Non-storable Commodity: Live Beef Cattle [J]. American Journal of Agricultural Economics 1974(56):271-79.

[25] Martin L, Garcia P. The Price-Forecasting Performance of Futures Markets for Live Cattle and Hogs: A Disaggregated Analysis [J]. American Journal of Agricultural Economics, 1981(63):209-15.

[26] Hokkio C, Rush M. Market Efficiency and Cointegration: An Application to Sterling and Deutschmark Exchange Rates [J]. Journal of International Money and Finance, 1989(8): 75-88.

[27]Bhattacharya P S, Singh H. An Explanation of Efficient Market Hypothesis and Unbiasedness Using Markov Switching Framework [DB]. SSRN, 2007.

[28]Rong Chen, Peilong Zheng. Unbiased estimates, the price discovery efficiency - the relationship between futures and spot price and futures market[J]. System Engineering Theory and Practice, 2008, 8:2-11.

[29]Xianghui Cai. Basic research on price discovery function of stock index futures [J]. Price Theory and Practice, 2009(10).

[30] Renhai Hua, Qingfu Liu. Research on price discovery ability between the stock index futures andstock index spot market[J]. Quantitative and Technical Economics, 2010(10).

[31] Yingying Xing. Function of the futures market price theory analysis-China's futures market[M].Peking: China Financial Publishing House, 2012, 8.

[32]ZhengWang. Research on price discovery function of treasury futures[D]. Chengdu: Southwestern University of Finance, 2013.

[33] Jian Ma. Correlation of treasuries spot market prices[J]. China Finance, 2013(22):84.

[34]Howard C T, Antonio D. A Risk-Return Measure of Hedging Effectiveness[J]. Journal of 
Financial and Quantitative Analysis, 1984(19):101-112.

[35] Mitchell M, Pulvino T, Stafford E. Limited arbitrage in equity markets [J]. Journal of Finance, 2002.

[36] Yang Yang. Treasury bonds futures arbitrage strategy analyses[J]. Bond Practice, 2014(3):51-56.

[37] Andrea A, Luca B, Olena C. No-Arbitrage Restrictions and the U.S. Treasury Market [J]. Economic Perspectives, 2012:55-74.

[38] Marcelo P, Alfonso D, Chris B. The Determinants of a Cross Market Arbitrage Opportunity: Theory and Evidence for the European Bond Market [J]. Ann Finance, 2014, 10:457-480.

[39] Lin Guan. Bond futures inter-temporal arbitrage quantitative model design-empirical test based on the actual treasury bond futures trading data in our country[J]. Business Administrator, 2015, 1:6-8.

[40] Han C H, Chang C H, Kuo C S, Yu S T. Robust Hedging Performance and Volatility Risk in Option Markets: Application to Standard and Poor's 500 and Taiwan index options[J]. International Review of Economics and Finance, 2015:1-14.

[41]Liang C X, Li S H. Option Pricing and Hedging in Incomplete Market Driven by Normal Tempered Stable process with Stochastic Volatility [J]. Journal of mathematical Analysis and Applications, 2015, 423:701-719. 